\title{
Infrastructure and health: the salutogenic approach, interdisciplinarity and new challenges for planning and design
}

\author{
Agnès Patuano \\ Landscape Architecture and Spatial Planning Group, \\ Wageningen University and Research, Wageningen, The Netherlands \\ Ralitsa Shentova \\ Environmental Systems Analysis Group, Wageningen University and Research, \\ Wageningen, The Netherlands, and \\ Ana Aceska \\ Cultural Geography Group, Wageningen University and Research, \\ Wageningen, The Netherlands
}

\begin{abstract}
Purpose - The purpose of the article is to present some preliminary findings and discussions points from a symposium on Public Outdoor Spaces and COVID-19 organised in Wageningen, The Netherlands, in June 2021. Design/methodology/approach - The article argues for a salutogenic perspective on infrastructure planning and design, dealing with the interplay between the ideas and practices of infrastructure planning and design and the outcomes of those ideas and practices for health.

Findings - Within that perspective, the coronavirus (COVID-19) crisis is seen as an opportunity to revive the importance of infrastructure in promoting health and well-being.

Originality/value - The salutogenic approach adds a much-needed new perspective on infrastructure planning and design, and also involves challenges both in research and practice, for the application of holistic principles to the design of new environments.
\end{abstract}

Keywords Salutogenesis, Infrastructure planning and design, Health, COVID-19, Interdisciplinarity

Paper type Viewpoint

\section{Introduction}

In the last few years, construction projects and their management have faced criticism for their lack of attention to projects' non-financial benefits and social performance (Caron et al., 2020; Goel et al., 2020). Previous studies have considered the importance for projects to be socially sustainable, with respect to their workforce, the project-affected community and the end-users or

(C) Agnès Patuano, Ralitsa Shentova and Ana Aceska. Published by Emerald Publishing Limited. This article is published under the Creative Commons Attribution (CC BY 4.0) licence. Anyone may reproduce, distribute, translate and create derivative works of this article (for both commercial and noncommercial purposes), subject to full attribution to the original publication and authors. The full terms of this licence may be seen at http://creativecommons.org/licences/by/4.0/legalcode.

The authors would like to thank the other participants of the 2021 "Public Outdoor Spaces and Covid-19" symposium organised in Wageningen, the Netherlands, for their insights during discussions, the WUR Aspasia committee for funding the symposium and the organisers of the joint ITTECOP and KHEOPS webinars for inspiring the topic of this paper. Many thanks to Sjerp de Vries and Jana Verboom for their support and guidance as supervisors of Ralitsa Shentova's master thesis, which was the basis for her contribution to this paper and the symposium.

Funding: The "Public Outdoor Spaces and Covid-19" symposium was funded by the WUR Aspasia Fund
Salutogenic infrastructures planning and design

Received 2 September 2021 Revised 25 December 2021 Accepted 13 January 2022

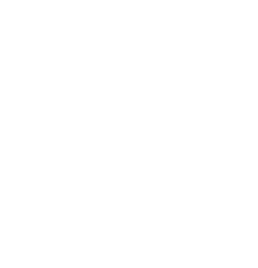


IJMPB

15,4

646

customers of the project's deliverable (Goel et al., 2020; Valdes-Vasquez and Klotz, 2013). These preoccupations are particularly relevant in light of the current health crisis caused by the propagation of COVID-19. With the aim to contribute to this ongoing conversation, in this paper we argue for the salutogenic approach to infrastructure design - an approach that introduces health outcomes into the interdisciplinary theories and practices of infrastructure planning and design.

In what follows, we explore the salutogenic approach applied to infrastructure design, focussing particularly on the contribution of green infrastructure, before tackling the topic of the COVID-19 crisis and the role played by infrastructure in this context. In addition, we present reflections on the challenges faced by practitioners and researchers wanting to explore salutogenic solutions. This paper presents part of the outcomes of the interdisciplinary symposium "Public Outdoor Spaces and COVID-19" that took place in Wageningen, the Netherlands, in June 2021.

\section{Salutogenesis: background, definition and relevance for the COVID-19 pandemic}

In 1948, the world entered a new sanitary age when the World Health Organisation (WHO) proposed to define health as "a state of complete physical, mental and social well-being and not merely the absence of disease or infirmity" (WHO, 1946, p. 1315). Once considered solely a physical or biological issue, under the responsibility of medicine, health is now seen as a holistic condition which concerns many different disciplines and fields of studies. Following this new perspective, Aaron Antonovsky, a medical sociologist in the 1980s developed the concept of salutogenesis (Mittelmark et al., 2017). This approach allowed the consideration of factors supporting health and wellness in the holistic sense described by WHO rather than focussing on what causes diseases. Within this perspective, human health and well-being are seen as a result of everyday interactions with the social, economic, cultural and physical environment. The salutogenic model of health considers that everything matters and everything is related. People who suffer from poor mental health, such as depression or anxiety, often tend to also suffer from poor physical health and vice versa. This of course has consequences on their social health, which, in turn, affects their mental health.

Antonovsky was particularly interested in the relationship between health, stress and coping, which was the title of his 1979 book in which he introduced salutogenesis (Mittelmark et al., 2017). Stress in itself is a natural and unavoidable reaction linked to evolutionary survival mechanisms (Grahn and Stigsdotter, 2003). However, a prolonged exposure to stressors can negatively affect health through the elevation of stress hormones and an imbalance amongst bodily systems such as the cardiovascular, skeletomuscular and neuroendocrine systems (Mazzi, 2021; Ulrich et al., 1991). A critical aspect of salutogenesis has, therefore, been to focus on mitigating this stress in order to limit its negative consequences on health (Mazzi, 2021; Mittelmark et al., 2017). Thus, Antonovsky introduced a new concept named "sense of coherence" which can be described as "the degree to which one finds life comprehensible by the ability to discern the patterns or predictability in a situation, believing one has the skills to manage or control the situation, and finding meaningfulness in the situation" (Mazzi, 2021, p. 339). Along these lines, salutogenesis can also take an "asset approach" to environmental analysis, whereby resources can be classified depending on whether they create or mitigate stress (Mazzi, 2021; Mittelmark et al., 2017). In this context, good health can be considered as depending on the interplay between environmental resources and sense of coherence (Maas et al., 2017). An individual with a higher sense of coherence might need fewer health-promoting resources, but "easily identifiable and useable resources might be crucial for engagement in health-promoting behaviour for people with a weaker sense of coherence" (Maas et al., 2017, p. 172). 
By linking environmental resources with health outcomes, salutogenesis offers a framework which is highly relevant to planners and designers when considering infrastructure projects. This framework is particularly relevant when rethinking the theories and practices of infrastructure planning and design in light of the COVID-19 pandemic. The COVID-19 pandemic is indeed a global health crisis. First, in the pre-1948 meaning of health, it is an airborne virus causing a precise pathology. But in the post-1948 meaning of health, it has also affected the mental and social well-being of millions of people over the world. Indeed, through the restrictions imposed on public life and public spaces, access and perceptions of the physical and social environment have shifted. Things which people used to take for granted, as easy as going to the shop for a bottle of milk, have now moved into the domains of fear and desire, which are sublimated by the sanitary crisis. It is difficult to predict the future at the best of times, but this crisis, which is for a lot of us unprecedented in our lifetime, also poses new challenges for infrastructure design in light of public health outcomes. Before we can think of rethinking infrastructure projects for the new normal, we need to look back and think of what the old normal meant, what the pros and cons were, what should be taken forward and what should be done with and what led us here in the first place.

\section{Salutogenic approach to infrastructure design}

When it comes to environmental design, the salutogenic approach is best illustrated by the health map proposed by Barton and Grant (2006) (Figure 1). Based on a previous model by
Salutogenic infrastructures planning and design

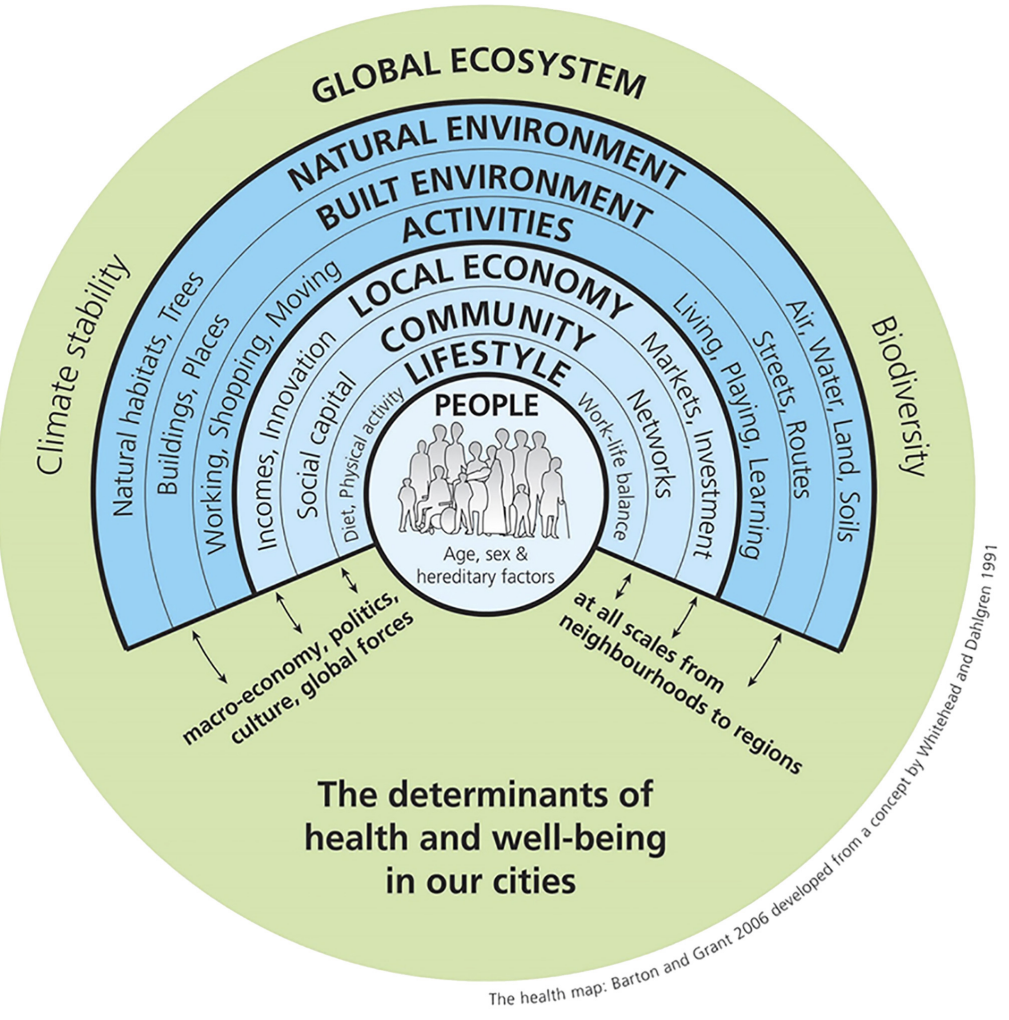

Source(s): From Barton and Grant (2006)

Figure 1. The health map 
IJMPB

15,4

\section{8}

Whitehead and Dahlgren (1991) but enhanced by an ecosystemic approach, the health map represents the various facets of our living environment which play a part in human health. A series of concentric spheres represent the various social, economic and environmental variables. Like in ecosystem theories, the living environment is represented as part of the global ecosystem on which it also depends. Wider cultural, economic and political contexts, which also affect well-being, are also represented as part of that ecosystem.

The core of the map is the genetic and physiological aspects of individuals, their age, gender and the hereditary factors which indicate whether or not they are likely to develop pathologies in their lifetime. The second sphere represents their social practices, such as their community, whether or not they are lonely but also their direct environment which indicates which local market they can or cannot access. The built environment is part of the third group of spheres, which is also containing the natural environment and human activities. This last sphere describes the factors influencing behaviours such as where people live and work and what they do, whether or not they can walk to work, what entertainment and leisure activities they have access to and the quality of the natural resources around them. Through this last sphere, the map essentially illustrates the role of planners and designers in determining the health of populations by considering the knock-on effects of their interventions. Indeed, these interventions can have implications: first, for the natural environment they thereby modify and second, on the pattern of human activities they affect. This is particularly clear in the case of infrastructure design.

\subsection{Salutogenic impact of infrastructure}

Generally, infrastructure can support health and well-being through "the distribution of resources, opportunities for activities and social meeting places that can facilitate social connectedness, possibilities for outdoor recreational activity, and active travel" (Maas et al., 2017, p. 174). In their paper presenting the health map, Barton and Grant (2006) take the example of a new road. The implementation of this new infrastructure might first affect human activities, such as travel behaviour and destinations, by connecting a neighbourhood to others. This change of activity, as well as the infrastructure itself, will also affect the natural environment at various scales, both local by creating more air pollution and global by increasing greenhouse gas emissions, as well as potentially fragmenting the landscape and affecting the movement of species. The new road will also have knock-on effects on the local economy by creating or delocalising activities. And finally, it will affect people's lifestyle choices by providing different opportunities for physical exercise such walking or cycling. These lifestyle changes may also affect the pattern of social networks, perhaps creating gentrification. It is, therefore, apparent that every level of health determinant, apart from the inherited characteristics at the core of the map, is affected to a certain extent.

\subsection{Green infrastructure}

Related to this new perspective on the health impact of infrastructure, the concept of green infrastructure, a "strategically planned network of natural and semi-natural areas" (European Commission, 2013), was also introduced. Indeed, the integration of natural elements into urban contexts has countless benefits from climate adaptation to biodiversity conservation and carbon sequestration. The creation and management of urban green spaces can also affect people's lifestyles through providing opportunities for physical activity, social contact as well as promoting local food production. Proximity and use of natural areas have, therefore, been shown to have wide-ranging health benefits for populations including improved mental health, reduced cardiovascular morbidity and mortality, obesity and risk of type 2 diabetes and improved pregnancy outcomes (see WHO, 2016 for a review of evidence). 
In these ways, urban nature is in line with the salutogenic approach, addressing multiple determinants of health and well-being in neighbourhoods. Green infrastructure can, therefore, be considered as a particularly salutogenic type of infrastructure, providing populations with opportunities to be in contact with nature as a basic human need.

\subsection{Diversity of populations}

An important aspect to take into account when considering accessibility is the opportunities and barriers that are faced by diverse populations. Indeed, there is often a clear link between socio-economic inequality and health inequality, meaning that socioeconomically deprived populations suffer from poorer health outcomes than others. The lack of recourses makes poor nations more exposed to inadequate infrastructure in relation to health outcomes (Campbell-Lendrum and Corvalan, 2007; Huq et al., 2003; McFarlane, 2008; Kraemer et al., 2011). Therefore, their need for salutogenic environments is greater than other populations.

This is particularly true when considering the impact of green infrastructure. Indeed, the presence of green space has been shown to provide an equigenic environment, bridging health disparities for different socio-economic profiles (Mitchell et al., 2015; Mitchell and Popham, 2008). Similarly, the relationship between amount of green space present in the environment and self-reported health was found to be stronger for lower-educated people (De Vries et al., 2003).

Economically, urban green space was also found to benefit deprived urban communities more than others, creating more equal socio-economic conditions (CABE, 2004). Therefore, scholars have suggested using urban green spaces to improve the health of disadvantaged communities (Jennings et al., 2016). This difference of impact can be at least partially explained by the importance of stress and stress mitigation within theories of salutogenesis. Deprived populations, being the ones who experience the most stress, are also the ones who can benefit most by its mitigation.

\subsection{Recommendations for salutogenic designs of infrastructure}

It is already common practice to carry out health impact assessments (HIA) when undertaking infrastructure projects. However, HIA have been found to not always be used very effectively or to primarily focus on biological and physical factors rather than integrating social or behavioural considerations (Nowacki, 2018). A salutogenic approach could provide a more holistic picture of the potential health risks or benefits of infrastructure projects.

For example, when considering the salutogenic design of transport infrastructures such as streets and roads, three main aspects could be taken into account: what, where and how. The "what" refers to the type of infrastructure which is created and whether or not it includes natural elements as part of its design. Street trees, for example, have been found to provide opportunities for cognitive restoration of mental fatigue (Lindal and Hartig, 2015), reduce urban heat island effect (Klemm et al., 2015) and even reduce crime (Kuo and Sullivan, 2001). Green infrastructure can, therefore, in this case be integrated with grey infrastructure. The "where" is to consider the connectivity and accessibility that is offered by the transport infrastructure. Indeed, one of the main factors linking, for example, natural outdoor spaces and health is the proximity of nearby greenery as represented by the travel distance (WHO, 2016). In this, the network of transport infrastructure and its connectivity to green infrastructure is critical. The "how" represents the modes of transport supported by the infrastructure or a different type of accessibility. Ensuring that all users can safely walk along it, or the provision of active travel opportunities, can also influence the health of populations.

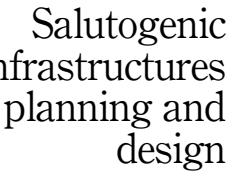


IJMPB

15,4

Along these lines, the inclusion of the local community is also key to ensure that infrastructural projects actually serve the needs of their users (Xiao and Hao, 2021; ValdesVasquez and Klotz, 2013). Numerous studies have shown that urban planning that takes into account positive health outcomes reinforces the need to draw on local knowledge (D'Onofrio and Trusiani, 2018; Frumkin et al., 2004; Northridge and Freeman, 2011).

3.5 Examples of good practice

Two successful examples of salutogenic infrastructure are the Mersey Forest project in Liverpool and the Fairfield Housing estate near Perth, UK. Both projects involved the local community in the planning and construction phases, ensuring that their needs are met and encouraging them to take ownership of the space, as well as to help maintain it afterwards. The Mersey Forest involved tree planting to transform a post-industrial landscape for social, environmental and economic regeneration (Ecosystems Knowledge Network, n.d.). It benefitted residents' physical and mental health, facilitated growing local food and created new sport facilities and wildlife areas (Vaandrager and Kennedy, 2017). Fairfield, too, went from one of the most deprived estates in the east of Scotland in 1984 to a thriving sustainable co-operative by 2000, whilst remaining social housing and creating jobs (World Habitat, 2017). In this case, affordable ecological construction lowered energy bills and negative health impacts from dampness (World Habitat, 2017).

These successful salutogenic projects involved partnerships between the private sector, local authorities and other public organisations and the community. Critical success factors were utilising the opportunities that different groups bring and the empowerment gained through collective engagement (Vaandrager and Kennedy, 2017). In practice, this is connected to strategic asset management and relational contracting. Moreover, creating integrated contracts that link the stages of design, construction and maintenance (Lenferink et al., 2013) can greatly help in developing salutogenic infrastructure. It would increase cooperation and accountability along the project life cycle and highlight synergies between the aims of different actors. Thus, in the process of planning, organisation, operation and management of a successful salutogenic project, it is critical to include these four groups: (1) experts (designers, technicians and interdisciplinary researchers); (2) business, funders and developers; (3) government authorities and (4) users and the local community. Such integrated and participatory approaches may require more resources and risks may still remain - as mentioned, different populations have different needs - but through them, priorities and standards of "success" can be defined so that the resulting projects can really serve the communities' well-being.

\section{Green and grey infrastructures during the COVID-19 crisis}

There is already overwhelming evidence that access to green space can support the health of populations (WHO, 2016). More evidence is now coming to light to show that, following salutogenic theories, accessing green spaces has helped mitigate the impact of the pandemic restrictions on populations' mental health.

\subsection{Salutogenic approach to green spaces during the pandemic}

Current literature has been investigating the effects of different types of green spaces during the pandemic. Primarily, visitation to green spaces has been shown to have shifted and that varied from country to country depending on restrictions measures. Some studies found an increase in visits to urban and peri-urban green areas (e.g. in the USA, in Grima et al., 2020), as well as small urban gardens nearby (e.g. in Italy) or tree-lined streets (e.g. in Spain and Israel) (Ugolini et al., 2020). In Spain, where lockdown measures were stricter, contact with private green spaces was more relevant for well-being, whereas in Portugal the association was 
stronger for contact with public green spaces (Ribeiro et al., 2021). Studies from Bulgaria and Japan indicate that even a green view from the window during the pandemic was linked with reduced symptoms of depression and anxiety (Dzhambov et al., 2021), as well as increased levels of self-esteem, life satisfaction and subjective happiness with greener views (Soga et al., 2021). It is important to note that in times of lockdown, seemingly simple elements like a green view and street trees proved to make a significant difference for well-being. Also, research from Sweden found that higher levels of greenness in the neighbourhood were associated with improved mental health and vitality, as well as fewer symptoms of depression, anxiety and lower perceived and cognitive stress (Lõhmus et al., 2021). In Scotland, psychological distress related to the pandemic was higher for participants in urban, deprived areas, with no access to residential outdoor space and who reported fewer visits to green spaces (Hubbard et al., 2021). More and more studies are emerging which illustrate the ways in which urban nature mitigated the negative impacts of COVID-19 and its associated containment measures. Moreover, urban dwellers themselves indicate that the outdoors helped them cope with COVID-19 restrictions (Guzman et al., 2021) and that they found green spaces to be very important for mental health benefits (Berdejo-Espinola et al., 2021; Grima et al., 2020). By cutting access to outdoor spaces, citizens seem to have realised how important that access was for their lives and individual well-being. Therefore, it is becoming increasingly recognised that nature embedded in the urban infrastructure is key for promoting good health, as well as mitigating negative impacts of public health crises for communities.

\subsection{The importance of considering infrastructure in the pandemic}

Beyond the green, grey infrastructures also played a part in the pandemic. Indeed, cities were found to be disproportionately more affected by the COVID-19 crisis than villages. According to a report of the United Nations, $90 \%$ of reported coronavirus cases until August 2020 worldwide are concentrated in urban areas (United Nations, 2020). The poor and marginalised urban population is particularly vulnerable. In their study on urban poor in India, Ghosh et al. (2020) argue that the predominance of the pandemic in cities has largely affected the urban poor living in a slum. The situation might be different in countries where the variation in urbanisation is too small to expect significant differences between the urban poor and the rest or between rural and urban areas. For example, recent research suggests that in the Netherlands, a country with a very small variation in urbanisation, the geography of the epidemic suggests more proportional urban and rural areas (Boterman, 2020).

Yet even though we have evidence to believe that the differences between urban and rural infrastructures in many Western countries are not significant and that many people, even those that live in rural areas, have access to good heath infrastructures, we witness a situation in which many urban Europeans and Americans imagine their post-COVID futures in a rural area. As Anderson (2017) and Koselleck (2004) claim, the idea of "otherness of the future" is inherent to crisis. To what extent urbanites in Western cities are really moving to rural areas is too early to say, as evidence is still based on estimations and journalistic reports. For example, in the UK the number of enquiries from Liverpool city dwellers looking for a village property has risen by $275 \%$ compared with 2019, whilst in Edinburgh and Birmingham enquiries for village property have risen by 205 and 186\% respectively (Marsh, 2020). Similar estimations in the USA point that page views for rural property listed on a large real estate website have risen ten times more than page views for properties in cities (Rose, 2020). These estimations do not represent actual sales or migration to villages. Yet, they indicate something important: in this pandemic, the city is the territory where struggles for different futures are most intense and visible. Unlike this pandemic, the previous ones caused reverse migrations in which people moved from villages to cities in quest for better health care and infrastructure (Butcher, 2020). Whilst then, the poor health infrastructures in villages and the lack of connectivity have eventually made people move

\section{Salutogenic infrastructures planning and design}


IJMPB

15,4

652

to cities and the advanced technology and infrastructures of our times and the possibility to work from home for many urbanites in Western countries have opened new possibilities for moving to rural areas in a quest for more green infrastructures, whilst keeping the same jobs and the accompanying lifestyles. This leads to the need to examine the complex physical, social and economic factors that have changed the perceptions of living in cities amongst urbanites in Western countries in this pandemic and have opened an opportunity to think of new creative ideas to improve cities and urban living environments.

\section{Risk and challenges of the salutogenic framework for practice and research 5.1 Practice}

One of the major limitations of this framework is the difficulty of defining what success looks like (Santos et al., 2014). As a processual approach in which health is a dynamic phenomenon unfolding and evolving over time through complex interactions, there are no existing standards of success one could aim for (Fachin and Langley, 2018). Therefore, examples of good practice may also be difficult to establish and recommendations differ on a case-by-case basis. Consider, for instance, the High Line in New York, one of the most famous parks of the 21st century and an example of the revitalisation of unused transport infrastructure. Originally intended as a community place where people could "walk through gardens, view art, experience a performance, savour delicious food or connect with friends" (The High Line, n.d.), it quickly became an example of how green spaces can create gentrification. Instead of supporting the health of the community, it drove it away (Wolch et al., 2014).

Furthermore, in order to support the equigenic effects of green infrastructure, it is also important to consider the needs of diverse groups. Populations that differ, for example, in terms of life stage, gender and levels of physical activity may have different needs when it comes to infrastructure, which presents another practical challenge and risks. For example, facilitating physical activity in a park can look different for children (e.g. having playing fields and playgrounds) compared to elderly or people with physical disabilities (e.g. having accessible paths) (Beute et al., 2020). For many, natural areas can also bring about feelings of fear and disgust due to undesirable animals (e.g. spiders and insects) and plants (e.g. poisonous species and allergens), perceived higher likelihood of crime, injury and disorientation (Patuano, 2020).

These risks can be mitigated in the planning, implementation and management of infrastructure. In the case of New York's High Line, changes in the planning process could have led to a different outcome: it highlights the need for cross-sectoral municipal planning efforts and for building more robust coalitions; in this case, it is between parks and housing organisations (Rigolon and Németh, 2018). Linking these actors together could have ensured the project remains affordable, bridging environmental and economic goals, thus avoiding gentrification. Also, involving health and ecology experts when designing a park, for example, could reduce the chances of undesirable and harmful animals and plants appearing. Examples like this, as well as the pandemic in general, highlight the strong association between infrastructure - both green and grey - and public health. Thus, involving relevant experts and ensuring coordination between different organisations and agencies are essential for addressing risks and challenges in salutogenic infrastructural projects and ensuring design for health outcomes.

Overall, a common language between researchers and practitioners is necessary (Mazzi, 2021; Caron et al., 2020; Nowacki, 2018). Indeed, the integration of HIA in project requires a common understanding of health (Nowacki, 2018). However, salutogenesis tends to complicate discussions, as there seems to be a misalignment between how the theory of salutogenesis is defined by scholars and the way that salutogenesis is reflected in architectural practice (Mazzi, 2021). Therefore, more awareness is required on what a wider definition of health such as the one proposed by salutogenesis can be (Nowacki, 2018). This could, in turn, raise awareness of the relevance of considering the health impacts when 
planning projects (Nowacki, 2018). Alternatively, the team in charge of project management should include experts with knowledge of health topics (Valdes-Vasquez and Klotz, 2013).

\subsection{Research}

The salutogenic approach is, by definition, interdisciplinary. Looking at the health map (Figure 1), elements as diverse as economy, lifestyle and social capital are as important as biodiversity, climate and built environment. Social sciences, natural sciences and design practices all need to work together to support the health of communities. And to understand the effectiveness of interventions requires considering all aspects at once.

In research, the first challenge is related to the provision of robust empirical evidence to support decisions taken in practice and the undertaking of HIA. Indeed, this often requires isolating precise relations of cause and effect, when a single shift such as the creation or destruction of a transport infrastructure might have a butterfly effect on the economy of a neighbourhood, its physical quality and its social component. These relationships are particularly hard to identify when conducting natural research projects that take place outside of a lab setting into the real world where relationships are complex and chaotic.

A second challenge is that the results of specific research projects on specific sites might not be reproducible in other projects. In the case of the COVID-19 research on access to outdoor environments, this can be illustrated by the differences in the results that are obtained by an international team of researchers who found that visits to green spaces had either decreased or increased depending on the type of green space (urban park, garden, tree-lined street, etc.), its location (inside or outside the town) and the country of study (Croatia, Israel, Italy, Lithuania, Slovenia or Spain) (Ugolini et al., 2020). There is no doubt that the COVID-19 crisis, though global, was experienced in wildly different ways in different contexts. In many ways, the inequalities that previously existed were only highlighted through the different environmental, cultural, economic and epidemiological approaches to the pandemic.

The third challenge is much more practical and refers to the difficulties of interdisciplinary communication. For the medical sciences, which heavily depend on positivist research and quantitative results, a holistic approach is difficult to operationalise. This can be illustrated in the rise of the "research through designing" methodology in architecture and landscape architecture disciplines. Such a methodology requires the thorough and systematic testing of design solutions to provide effective and evidence-based design solutions (Lenzholzer et al., 2013). When applying this methodology to a salutogenic framework, it is apparent that testing hypothetical design solutions for their ability to support the health of real communities is at best complex and at worst impossible. This is linked to the first challenge on the difficulty of isolating reliable cause and effect relationships whereby a single design solution cannot be expected to yield a specific effect amongst the populations and to the second challenge whereby the complexity of real relationships makes each solution site-specific and not necessarily replicable to other contexts.

Within this challenge of interdisciplinary research, lies also the narrow focus required by academic expertise. As one becomes an expert in its field, the understanding of other disciplines become more distant and simplified. Therefore, some experts in environmental sciences might have binary understandings of medical sciences whereby people can be considered either healthy or not as opposed to the wide spectrum that health conditions might span. And, in turn, medical professionals can sometimes have a simplified vision of environmental sciences whereby biodiversity is considered an ultimate goal without considering the trade-offs that might operate in that context and the wide diversity of forms and shape biodiversity can take. Any salutogenic endeavour, requiring the collaboration of both sides of the scientific isle, will need to ensure these communications hurdles are addressed in order for effective research to be carried out.

\section{Salutogenic infrastructures planning and design}


IJMPB

15,4

654

The final challenge is the most critical one when considering the current health crisis. Salutogenic research requires the co-creation of knowledge between academic research and practice. Beyond a shared language, it also requires a certain political and public engagement that heavily depends on personal positions and ideologies. In the case of green infrastructures, questions of environmental integrity often have wide implications for participants' nature connectedness and place identity. The different values of nature have ties to cultural, spiritual and personal identities, which make these debates difficult to address and solve when it comes to decision-making. If it is difficult to reliably prove that salutogenic design has a significant impact on public health, it is equally easy to debate it.

\section{COVID-19 as a window of opportunity}

The current context seems to have somewhat erased the need for such debates. A review of the emerging questions regarding the impact of COVID-19 and public spaces noted that the pandemic might accelerate the inclusion of health criteria into the design of public spaces (Honey-Rosés et al., 2020). Although health considerations in urban planning and design are not new, this current health crisis might revive the interest of stakeholders and decisionmakers for actively promoting healthy environments.

In the past, pandemics have proven powerful drivers for change both for grey and green infrastructure. In the 19th century, the cholera outbreak led to London's improved sewers and waste management system after it was revealed that the disease was caused by the mixing of clean drinking water with wastewater (Eltarabily and Elghezanwy, 2020). In the aftermath of the epidemic, the Select Committee on Public Walks reported to the English Parliament the need for open, recreational spaces in urban areas and demanded new legislation requiring every town to establish a public walk or park to improve the living conditions of the populations (Ward Thompson, 2011).

However, a salutogenic perspective on the coronavirus pandemic requires to not solely target the cause and mode of the propagation of the virus, but to radically rethink our environment in all its dimensions to consider every way in which our lives were affected by both the virus and our response to it. On a physical level, this might mean widening out the streets to allow for social distancing and promoting hand washing. But it might also mean preventing some of the co-morbidities, which increased the severity of the illness, such as diabetes, cardiovascular diseases and overweight, by providing more opportunities for physical exercise through walking, running and cycling and supporting mental health. Some important recommendations have already been formulated, such as paying more attention to the neighbourhood scale, decentralising services and promoting mixed-use developments, making use of flexible design, etc. (UN-Habitat, 2021; UN-Habitat and WHO, 2020).

\section{Conclusion}

Public health crises have transformed urban public spaces in the past, and similarly, the current pandemic presents a moment to re-evaluate how cities and neighbourhoods are designed and maintained and to design health-promoting environments into cities. Therefore, this pandemic, as deadly and disastrous as it is, is also an opportunity to bring issues of public health back into the realm of urban and infrastructure design and to explore the responsibilities of planners and designers in the health of populations. Salutogenesis as a conceptual framework allows us to consider both the physical and mental repercussions of this crisis and to come up with new, creative ideas to improve our cities and living environments going forward. Whether this renewed awareness can help us overcome the challenges of interdisciplinary salutogenic research and whether it will lead to permanent transformations still remains to be seen. 


\section{References}

Anderson, B. (2017), "Emergency futures: exception, urgency, interval, hope", The Sociological Review, Vol. 65 No. 3, pp. 463-477.

Barton, H. and Grant, M. (2006), "A health map for the local human habitat", Journal of the Royal Society for the Promotion of Health, Vol. 126 No. 6, pp. 252-253.

Berdejo-Espinola, V., Suárez-Castro, A.F., Amano, T., Fielding, K.S., Oh, R.R.Y. and Fuller, R.A. (2021), "Urban green space use during a time of stress: a case study during the COVID-19 pandemic in Brisbane, Australia”, People and Nature, Vol. 3 No. 3, pp. 597-609, doi: 10.1002/PAN3.10218.

Beute, F., Andreucci, M.B., Lammel, A., Davies, Z., Glanville, J., Keune, H., Marselle, M., O’Brien, L.A., Olszewska-Guizzo, A., Remmen, R., Russo, A. and de Vries, S. (2020), Types and Characteristics of Urban and Peri-Urban Green Spaces Having an Impact on Human Mental Health and Wellbeing, Report Prepared by an EKLIPSE Expert Working Group, UK Centre for Ecology and Hydrology, Wallingford.

Boterman, W.R. (2020), "Urban-rural polarization in times of the corona outbreak? The early demographic and geographic patterns of the SARS-COV-2 epidemic in the Netherlands", Tijdschrift voor Economische en Sociale Geografie, Vol. 111 No. 3, pp. 513-529.

Butcher, A. (2020), "Moving to the country: history repeats itself as urbanites flee virus-hit cities for rural retreats", The Telegraph, 26 May, available at: https:/www.telegraph.co.uk/global-health/science-anddisease/moving-country-history-repeats-urbanites-flee-virus-hit-cities/ (accessed 21 December 2021).

CABE (2004), The Value of Public Space: How High-Quality Parks and Public Spaces Create Economic, Social and Environmental Value, Commission for Architecture and the Built Environment (CABE), London.

Campbell-Lendrum, D. and Corvalan, C. (2007), "Climate change and developing-country cities: implications for environmental health and equity", Journal of Urban Health, Vol. 84, pp. 109-117.

Caron, M.A., Radu, C. and Drouin, N. (2020), "Integration of non-financial benefits: a systematic review for engaged scholars", International Journal of Managing Projects in Business, Vol. 14 No. 1, pp. 36-58.

De Vries, S., Verheij, R.A., Groenewegen, P.P. and Spreeuwenberg, P. (2003), "Natural environments healthy environments? An exploratory analysis of the relationship between greenspace and health”, Environment and Planning A, Vol. 35 No. 10, pp. 1717-1731.

D'Onofrio, R. and Trusiani, E. (2018), Urban Planning for Healthy European Cities, Springer, Cham.

Dzhambov, A., Lercher, P., Browning, M., Stoyanov, D., Petrova, N., Novakov, S. and Dimitrova, D. (2021), "Does greenery experienced indoors and outdoors provide an escape and support mental health during the COVID-19 quarantine?”, Environmental Research, Vol. 196, doi: 10.1016/J. ENVRES.2020.110420.

Ecosystems Knowledge Network (n.d.), The Mersey Forest, available at: https://ecosystemsknowledge. net/mersey-forest-0 (accessed 16 December 2021).

Eltarabily, S. and Elghezanwy, D. (2020), "Post-pandemic cities-the impact of COVID-19 on cities and urban design", Architecture Research, Vol. 10 No. 3, pp. 75-84.

European Commission (2013), Building a Green Infrastructure for Europe, Publications Office of the European Union, Luxembourg.

Fachin, F.F. and Langley, A. (2018), "Researching organizational concepts processually: the case of identity", Cassel, C., Cunliffe, A. and Grandy, G. (Eds), SAGE Handbook of Qualitative Business and Management Research Methods, Sage Publications, London, pp. 308-327.

Frumkin, H., Lawrence, F. and Jackson, R. (2004), Urban Sprawl and Public Health: Designing, Planning, and Building for Healthy Communities, Island Press, Washington.

Ghosh, S., Seth, P. and Tiwary, H. (2020), "How does covid-19 aggravate the multidimensional vulnerability of slums in India? A commentary”, Social Sciences and Humanities Open, Vol. 2 No. $1,100068$.
Salutogenic infrastructures planning and design 
IJMPB

15,4

Goel, A., Ganesh, L.S. and Kaur, A. (2020), "Project management for social good: a conceptual framework and research agenda for socially sustainable construction project management", International Journal of Managing Projects in Business, Vol. 13 No. 4, pp. 695-726.

Grahn, P. and Stigsdotter, U.A. (2003), "Landscape planning and stress", Urban Forestry and Urban Greening, Vol. 2 No. 1, pp. 1-18, doi: 10.1078/1618-8667-00019.

Grima, N., Corcoran, W., Hill-James, C., Langton, B., Sommer, H. and Fisher, B. (2020), "The importance of urban natural areas and urban ecosystem services during the COVID-19 pandemic", PLoS One, Vol. 15 No. 12, e0243344, doi: 10.1371/journal.pone.0243344.

Guzman, V., Garrido-Cumbrera, M., Braçe, O., Hewlett, D. and Foley, R. (2021), “Associations of the natural and built environment with mental health and wellbeing during COVID-19: Irish perspectives from the GreenCOVID study", The Lancet Global Health, Vol. 9 No. S20, doi: 10. 1016/s2214-109x(21)00128-5.

Honey-Rosés, J., Anguelovski, I., Chireh, V.K., Daher, C., van den Bosch, C.K., Litt, J.S., Mawani, V., McCall, M.K., Orellana, A., Oscilowicz, E., Sánchez, U., Senbel, M., Tan, X., Villagomez, E., Zapata, O. and Nieuwenhuijsen, M.J. (2020), "The impact of COVID-19 on public space: an early review of the emerging questions-design, perceptions and inequities", Cities and Health, pp. 1-17, doi: 10.1080/23748834.2020.1780074.

Hubbard, G., den Daas, C., Johnston, M., Murchie, P., Ward Thompson, C. and Dixon, D. (2021), “Are rurality, area deprivation, access to outside space, and green space associated with mental health during the COVID-19 pandemic? A cross sectional study (CHARIS-E)", International Journal of Environmental Research and Public Health 2021, Vol. 18 No. 8, doi: 10.3390/ IJERPH18083869.

Huq, S., Rahman, A., Konate, M., Sokona, Y. and Reid, H. (2003), Mainstreaming Adaptation to Climate Change in Least Developed Countries, Russell Press, Nottingham.

Jennings, V., Larson, L. and Yun, J. (2016), “Advancing sustainability through urban green space: cultural ecosystem services, equity, and social determinants of health", International Journal of Environmental Research and Public Health, Vol. 13 No. 2, doi: 10.3390/ijerph13020196.

Klemm, W., Heusinkveld, B.G., Lenzholzer, S. and van Hove, B. (2015), "Street greenery and its physical and psychological impact on thermal comfort", Landscape and Urban Planning, Vol. 138, pp. 87-98.

Koselleck, R. (2004), Futures Past: On the Semantics of Historical Time, trans. K. Tribe, Columbia University Press, New York.

Kraemer, A., Khan, M.M.H. and Jahn, H.J. (2011), "Public health in megacities and urban areas: a conceptual framework", in Kraemer, A., Khan, M.M.H. and Kraas, F. (Eds), Health in Megacities and Urban Areas, Springer-Verlag, Berlin, pp. 3-20.

Kuo, F.E. and Sullivan, W.C. (2001), "Environment and crime in the inner city: does vegetation reduce crime?", Environment and Behavior, Vol. 33 No. 3, pp. 343-367, doi: 10.1177/0013916501333002.

Lenferink, S., Tillema, T. and Arts, J. (2013), "Towards sustainable infrastructure development through integrated contracts: experiences with inclusiveness in Dutch infrastructure projects", International Journal of Project Management, Vol. 31 No. 4, pp. 615-627, doi: 10.1016/J. IJPROMAN.2012.09.014.

Lenzholzer, S., Duchhart, I. and Koh, J. (2013), "Research through designing' in landscape architecture", Landscape and Urban Planning, Vol. 113, pp. 120-127.

Lindal, P.J. and Hartig, T. (2015), "Effects of urban street vegetation on judgments of restoration likelihood", Urban Forestry and Urban Greening, Vol. 14 No. 2, pp. 200-209, doi: 10.1016/j.ufug. 2015.02.001.

Lõhmus, M., Stenfors, C.U.D., Lind, T., Lauber, A. and Georgelis, A. (2021), "Mental health, greenness, and nature related behaviors in the adult population of Stockholm county during COVID-19related restrictions", International Journal of Environmental Research and Public Health 2021, Vol. 18 No. 6, doi: 10.3390/IJERPH18063303. 
Maas, R., Lillefjell, M. and Espnes, G.A. (2017), “The application of salutogenesis in cities and towns", in Mittelmark, M.B., Sagy, S., Eriksson, M., Bauer, G.F., Pelikan, J.M., Lindström, B. and Espnes, G.A. (Eds), The Handbook of Salutogenesis, Springer, New York, pp. 171-180, doi: 10.1007/978-3319-04600-6.

Marsh, S. (2020), "Escape to the country: how Covid is driving an exodus from Britain's cities", The Guardian, 26 September, available at: https://www.theguardian.com/world/2020/sep/26/escapecountry-covid-exodus-britain-cities-pandemic-urban-green-space.

Mazzi, A. (2021), "Toward a unified language (and application) of salutogenic design: an opinion paper", HERD: Health Environments Research and Design Journal, Vol. 14 No. 2, pp. 337-349.

McFarlane, C. (2008), "Sanitation in Mumbai's informal settlements: state, 'slum', and infrastructure", Environment and Planning A, Vol. 40 No. 1, pp. 88-107.

Mitchell, R. and Popham, F. (2008), "Effect of exposure to natural environment on health inequalities: an observational population study", The Lancet, Vol. 372 No. 9650, pp. 1655-1660, doi: 10.1016/ S0140-6736(08)61689-X.

Mitchell, R., Richardson, E.A., Shortt, N.K. and Pearce, J.R. (2015), "Neighborhood environments and socioeconomic inequalities in mental well-being", American Journal of Preventive Medicine, Vol. 49 No. 1, pp. 80-84, doi: 10.1016/j.amepre.2015.01.017.

Mittelmark, M.B., Sagy, S., Eriksson, M., Bauer, G.F., Pelikan, J.M., Lindström, B. and Espnes, G.A. (2017), The Handbook of Salutogenesis, Springer, New York.

Northridge, M.E. and Freeman, L. (2011), "Urban planning and health equity", Journal of Urban Health: Bulletin of the New York Academy of Medicine, Vol. 88 No. 3, doi: 10.1007/s11524-0119558-5.

Nowacki, J. (2018), "The integration of health into environmental assessments - with a special focus on strategic environmental assessment", Dissertation at the University Bielefeld, Germany, WHO Regional Office for Europe, Copenhagen.

Patuano, A. (2020), "Biophobia and urban restorativeness", Sustainability, Vol. 12 No. 10, 4312, doi: 10. 3390/SU12104312.

Ribeiro, A.I., Triguero-Mas, M., Santos, C.J., Gómez-Nieto, A., Cole, H., Anguelovski, I., Silva, F.M. and Baró, F. (2021), "Exposure to nature and mental health outcomes during COVID-19 lockdown. A comparison between Portugal and Spain”, Environment International, Vol. 154, 106664, doi: 10. 1016/J.ENVINT.2021.106664.

Rigolon, A. and Németh, J. (2018), “'We're not in the business of housing': environmental gentrification and the nonprofitization of green infrastructure projects", Cities, Vol. 81, pp. 71-80, doi: 10.1016/ J.CITIES.2018.03.016.

Rose, J. (2020), "Time to move? Data suggests Americans may flee to rural areas post-COVID”, Forbes, 6 August, available at: https://www.forbes.com/sites/jrose/2020/08/06/time-to-move-data-suggestsamericans-may-flee-to-rural-areas-post-covid/?sh=34f1aa837161 (accessed 21 December 2021).

Santos, C., Santos, V., Tavares, A. and Varajão, J. (2014), "Project management success in health-the need of additional research in public health projects", Procedia Technology, Vol. 16, pp. 1080-1085.

Soga, M., Evans, M.J., Tsuchiya, K. and Fukano, Y. (2021), “A room with a green view: the importance of nearby nature for mental health during the COVID-19 pandemic", Ecological Applications, Vol. 31 No. 2, e2248, doi: 10.1002/eap.2248.

The High Line (n.d), Overview, available at: https:/www.thehighline.org/about/ (accessed 12 December 2021).

Ugolini, F., Massetti, L., Calaza-Martínez, P., Cariñanos, P., Dobbs, C., Ostoić, S.K., Marin, A.M., Pearlmutter, D., Saaroni, H., Šaulienè, I., Simoneti, M., Verlič, A., Vuletić, D. and Sanesi, G. (2020), "Effects of the COVID-19 pandemic on the use and perceptions of urban green space: an international exploratory study", Urban Forestry and Urban Greening, Vol. 56, 126888, doi: 10. 1016/j.ufug.2020.126888.
Salutogenic infrastructures planning and design 
IJMPB

15,4

658

Ulrich, R.S., Simons, R.F., Losito, B.D., Fiorito, E., Miles, M.A. and Zelson, M. (1991), "Stress recovery during exposure to natural and urban environments", Journal of Environmental Psychology, Vol. 11 No. 3, pp. 201-230.

UN-Habitat (2021), Cities and Pandemics: Towards a More Just, Green and Healthy Future, available at: https://unhabitat.org/sites/default/files/2021/03/cities_and_pandemics-towards_a_more_ just_green_and_healthy_future_un-habitat_2021.pdf (accessed 24 June 2021).

UN-Habitat and World Health Organisation (2020), Integrating Health in Urban and Territorial Planning: A Sourcebook, Geneva, available at: https://apps.who.int/iris/bitstream/handle/10665/ 331678/9789240003170-eng.pdf (accessed 24 June 2021).

United Nations (2020), Coronavirus: Reshape the Urban World to Aid "Ground Zero" Pandemic Cities, available at: https://news.un.org/en/story/2020/07/1069041 (accessed 24 June 2021).

Vaandrager, L. and Kennedy, L. (2017), "The application of salutogenesis in communities and neighbourhoods", in Mittelmark, M.B., Sagy, S., Eriksson, M., Bauer, G.F., Pelikan, J.M., Lindström, B. and Espnes, G.A. (Eds), The Handbook of Salutogenesis, Springer, New York, pp. 159-170, doi: 10.1007/978-3-319-04600-6.

Valdes-Vasquez, R. and Klotz, L.E. (2013), "Social sustainability considerations during planning and design: framework of processes for construction projects", Journal of Construction Engineering and Management, Vol. 139 No. 1, pp. 80-89.

Ward Thompson, C. (2011), "Linking landscape and health: the recurring theme", Landscape and Urban Planning, Vol. 99 Nos 3-4, pp. 187-195.

Whitehead, M. and Dahlgren, C. (1991), "What can we do about inequalities in health", The Lancet, Vol. 338, pp. 1059-1063.

Wolch, J.R., Byrne, J. and Newell, J.P. (2014), "Urban green space, public health, and environmental justice: the challenge of making cities "just green enough", Landscape and Urban Planning, Vol. 125, pp. 234-244, doi: 10.1016/j.landurbplan.2014.01.017.

World Habitat (2017), Fairfield Housing Co-operative - World Habitat Awards, available at: https:// world-habitat.org/world-habitat-awards/winners-and-finalists/fairfield-housing-co-operative/ \#award-content (accessed 16 December 2021).

World Health Organization (1946), "Constitution of the world health organization", American Journal of Public Health, Vol. 36 No. 11, pp. 1315-1323.

World Health Organization (2016), Urban Green Spaces and Health: A Review of the Evidence, World Health Organization, Geneva.

Xiao, H. and Hao, S. (2021), "Public participation in infrastructure projects: an integrative review and prospects for the future research", Engineering, Construction and Architectural Management, Vol. ahead-of-print No. ahead-of-print, doi: 10.1108/ECAM-06-2021-0495.

\section{Corresponding author}

Agnès Patuano can be contacted at: agnes.patuano@wur.nl

For instructions on how to order reprints of this article, please visit our website:

www.emeraldgrouppublishing.com/licensing/reprints.htm

Or contact us for further details: permissions@emeraldinsight.com 